\title{
A NEW SPECTROPHOTOMETRIC CUVETTE HOLDER FOR LOW TEMPERATURE STUDIES; ITS APPLICATION TO THE STUDY OF CARBONMONOXYHEMOGLOBIN OXIDATION RATE
}

\author{
ANDREA MOSCA ${ }^{1}$, ALBERTO MUSETTI ${ }^{2}$ and MICHELE SAMAJA ${ }^{1}$ \\ ${ }^{1}$ Cattedra di Enzimologia, via Celoria 2, Milan, and ${ }^{2}$ Istituto Scientifico San Raffaele, \\ Segrate, Milan, Italy
}

(Received 8 May 1979; accepted 18 June 1979)

A new spectrophotometric cuvette holder to be used for subzero temperature is described. The device is easily adaptable to a commercial spectrophotometer and it was checked down to $-40^{\circ} \mathrm{C}$. Satisfactory mixing of the reactants contained in the cuvette at low temperatures is attained using a special stirrer and suitable solution volumes. The rate of carbonmonoxyhemoglobin oxidation by $\mathrm{K}_{3} \mathrm{Fe}(\mathrm{CN})_{6}$ at different subzero temperatures has been studied using this apparatus; the results are in agreement with the extrapolated data at room temperature.

Key words: subzero spectrophotometry; antifreezing agents; carbonmonoxyhemoglobin oxidation; intermediate compounds.

\section{INTRODUCTION}

The study of biochemical reactions at temperatures below zero requires specialized instrumentation, not easily available commercially. Pioneer work in the development of suitable techniques for low temperature work has been carried out by Douzou and coworkers and has been reviewed recently [1]. In this paper we report the details of a simple, anaerobic cuvette holder for spectrophotometric work at subzero temperatures to be used with normal commercial glass or quartz cuvettes with a $1 \mathrm{~cm}$ pathlength. The cuvette holder may be adapted for use with most of the commercial spectrophotometers. Tests on the performances of this device are reported, together with the study of the optical properties of carbonmonoxyhemoglobin and its rate of oxidation to methemoglobin at temperatures ranging between 0 and $-25^{\circ} \mathrm{C}$.

Abbreviations: $\mathrm{HbCO}$, carbonmonoxyhemoglobin; $\mathrm{Hb}^{+}$, methemoglobin; $\mathrm{HbO}_{2}$, oxyhemoglobin. 


\section{MATERIALS AND METHODS}

\section{Description of the cuvette holder}

Figs. 1A and B show the side and top views, respectively, of the cuvette holder. It is made of two parts, an inner part of brass (Fig. 1A, a) and an outer insulating part of moplen (b). Two hose connections (c) provide the circulation of a suitable coolant into the inner block. The inlet $(d)$ can be connected to a cylinder of nitrogen or dry air. A gas flow of $400 \mathrm{ml} / \mathrm{min}$ was found adequate to prevent ice formation on the windows of the cuvette. The gas flows from $(d)$ to outlets $(o)$ and $\left(o^{\prime}\right)$. The plunger $(e)$ is provided with an o-ring seal to make the whole system anaerobic. The upper part of the insulating block (f) can be easily removed to provide access to the cell. The plunger has a $2 \mathrm{~mm}$ hole on top to allow control of the temperature of the cuvette's contents, or injection of reactants. The motor $(h)$ is coupled to a teflon-covered magnet ( $\mathrm{g}$ ) which is used to stir the contents of the cuvette. A $90 \mathrm{~W}$ heating element (i), connected to a $24 \mathrm{~V}$ D.C. power supply, is located in contact with the brass inner part and is used to bring the block up rapidly to room temperature.
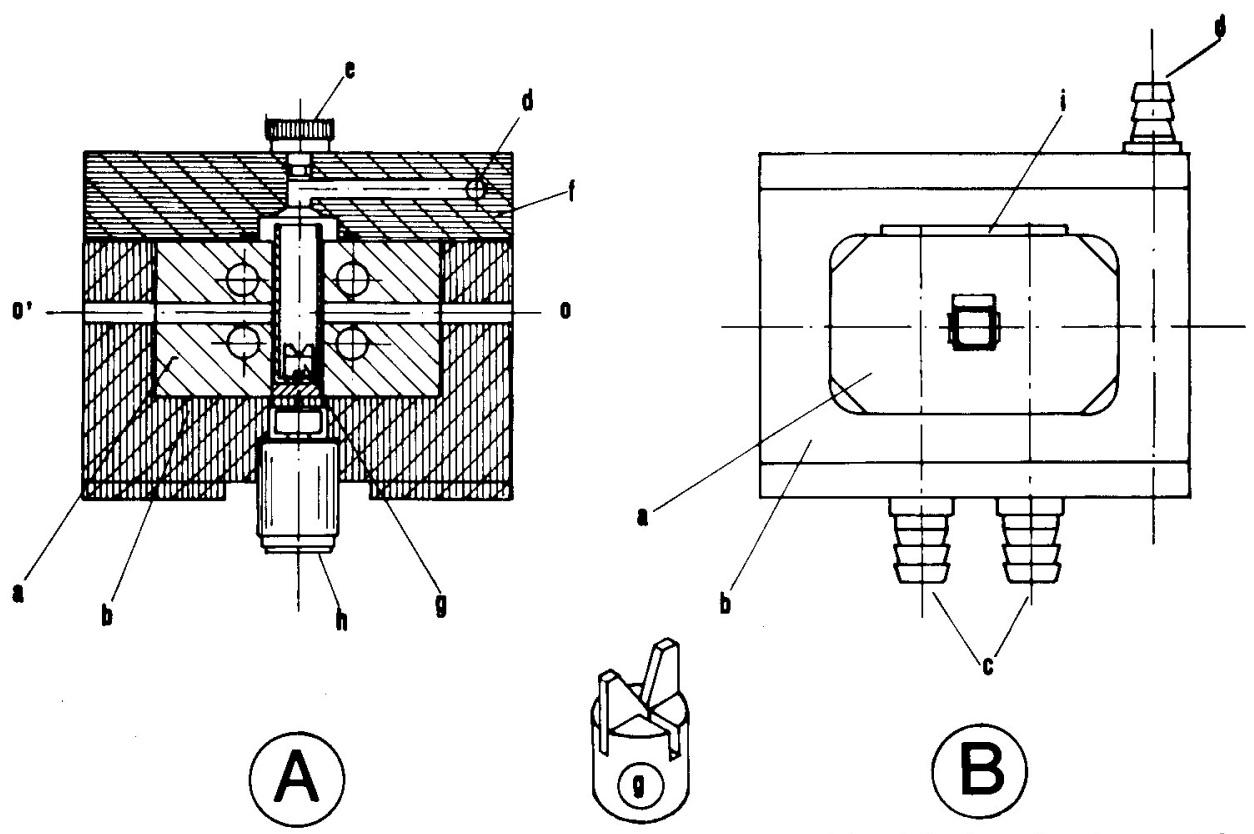

Fig. 1. Side view (A) and top view (B) of the cuvette holder. The top view is seen taken without the removable moplen upper part. a, inner brass part; b, insulating moplen cover; c, brass hose connections for the circulation of the coolant; $d$, gas flow inlet; e, plexiglas plunger to provide the anaerobicity of the cuvette; $f$, upper part (removed in $B$ ) of the cuvette holder; g, model of the teflon-covered magnetic stirrer; h, I.C. stirring motor; $o$ and $o^{\prime}$, light paths and gas outlets; $i, 90 \mathrm{~W}$ heating element. 
The cuvette holder shown in Fig. 1 was designed to fit into the sample compartment of an ACTA III Beckman spectrophotometer. Cooling of the cuvette was obtained by circulating refrigerated liquids supplied by a standard laboratory apparatus. Two kinds of organic solvents were used as refrigerating fluids: a $50 \%(\mathrm{v} / \mathrm{v})$ mixture of ethylene glycol with water and pure ethylene trichloride (Trieline). Connections between the apparatus and the cuvette holder were made with silicon tubing when the ethylene glycol mixture was used, and with vyton tubing in the case of ethylene trichloride. All connections were covered by $11 \mathrm{~mm}$ thick neoprene tubing to provide thermal insulation. During the spectrophotometric measurements the reference cuvette was covered by gauze in order to reduce the light intensity of the reference beam.

\section{Hemoglobin preparation}

Hemoglobin was prepared as described by Kilmartin and Rossi-Bernardi [2]. $\mathrm{Hb}^{+}$solutions were prepared by the oxidation of hemoglobin at room temperature with a $20 \%$ molar excess of solid $\mathrm{K}_{3} \mathrm{Fe}(\mathrm{CN})_{6}$. The solution was then gel-filtered through a G-25 Sephadex column using a $20 \mathrm{mM}$ phosphate buffer, $\mathrm{pH} 6.4$ at $25^{\circ} \mathrm{C}$, as eluant. For the study of $\mathrm{HbCO}$ oxidation, various amounts of $0.5 \mathrm{M} \mathrm{K}_{3} \mathrm{Fe}(\mathrm{CN})_{6}$ in a $50 \%(\mathrm{v} / \mathrm{v})$ ethylene glycol buffer were added to the $\mathrm{HbCO}$ solution at the required temperature in the cuvette.

\section{RESULTS AND DISCUSSION}

\section{Rate of temperature equilibration and mixing time}

Fig. 2 shows the rate of temperature equilibration of a $3.0 \mathrm{ml}$ sample contained in the cuvette. The flow of the coolant through the system was $10 \mathrm{ml} / \mathrm{s}$. Temperatures lower than $-40^{\circ} \mathrm{C}$ were not investigated owing to the limited power of the refrigerating apparatus.

Experiments were carried out to investigate the effect of the viscosity of the solution contained in the cuvette on the mixing time of small injected volumes of reactant. Fig. $3 \mathrm{~A}$ shows the absorbance change following the rapid injection $(<1 \mathrm{~s})$ of $50 \mu \mathrm{l} \mathrm{HbO}_{2}$ solution into a $1: 1$ mixture of ethylene glycol and water at $-30^{\circ} \mathrm{C}$. Fig. $3 \mathrm{~B}$ refers to an identical experiment in which the same amount of protein was injected into the aqueous solution at $25^{\circ} \mathrm{C}$. It is apparent from the data of Fig. $3 \mathrm{~A}$ that a decrease in absorbance (about $8 \%$ of the final value) follows the initial rapid change due to the injection of the protein. Visual inspection of the cuvette revealed that this effect is due to incomplete mixing of the contents of the cuvette. This may be possibly due to the square conformation of the cuvette. The effect was found to be roughly proportional to the viscosity of the solution and has to be taken into account for precise work in the time range $0-100 \mathrm{~s}$ after mixing. 


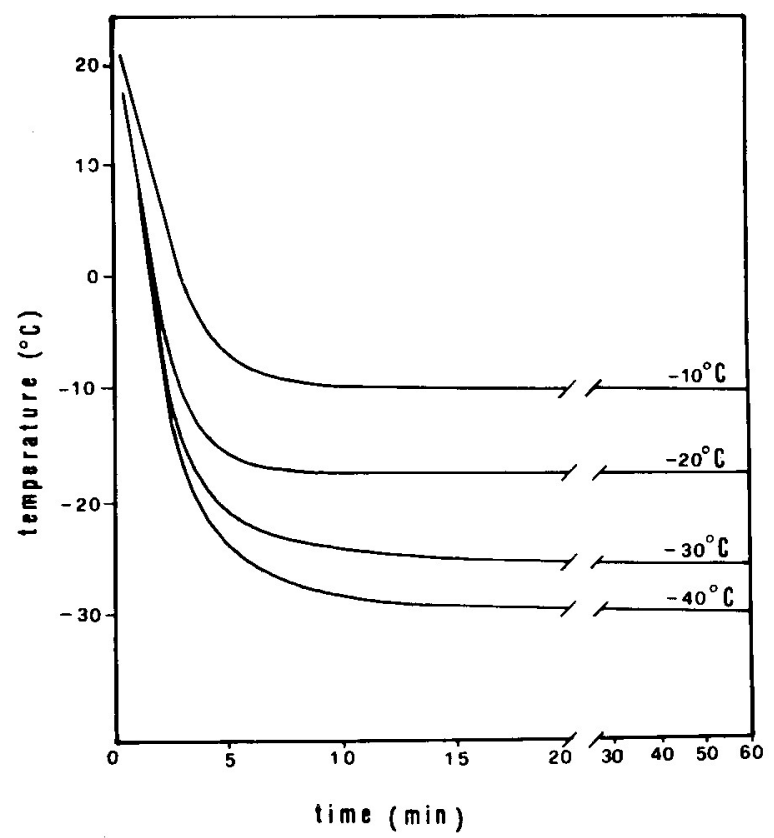

Fig. 2. Kinetics of the temperature decrease when a $3.0 \mathrm{ml}$ sample was used. The actual temperature, recorded inside the cuvette by a thermal sensor, is shown by the ordinates, while the temperature of the coolant is marked on the right. The thermal loss at very low temperatures seems to occur at the interface between the cuvette and the brass holder. $15 \mathrm{~min}$ is considered long enough to attain a complete temperature equilibration, regardless of the temperature of the coolant and its composition (ethylene glycol or ethylene trichloride) since the resulting flow was the same although the relative viscosities were quite different.

\section{Determination of spectra at low temperature}

In order to check the optical performance of the device described in Fig. 1, a series of experiments was performed on the optical properties of $\mathrm{HbCO}$ at various wavelengths. The optical alignment of the system was examined by running spectra of $\mathrm{HbCO}$ at room temperature using alternately a standard cuvette holder and the cuvette holder described in this paper. The spectra obtained by the two procedures showed a difference in absorbance over the wavelength range $490-650 \mathrm{~nm}$ of not greater than $1 \%$, i.e. within the experimental error. If, however, a $50 \%(\mathrm{v} / \mathrm{v})$ ethylene glycol solution was used at room temperature, absorbance values were found to vary with time, an indication that some protein denaturation occurred under these conditions. In order to obtain reproducible results, at least for the investigation of the optical properties of heme proteins, the protein solution was diluted to a final $1: 1$ ratio with ethylene glycol by gradual addition of the organic solvent and synchronous lowering of the temperature. By this 


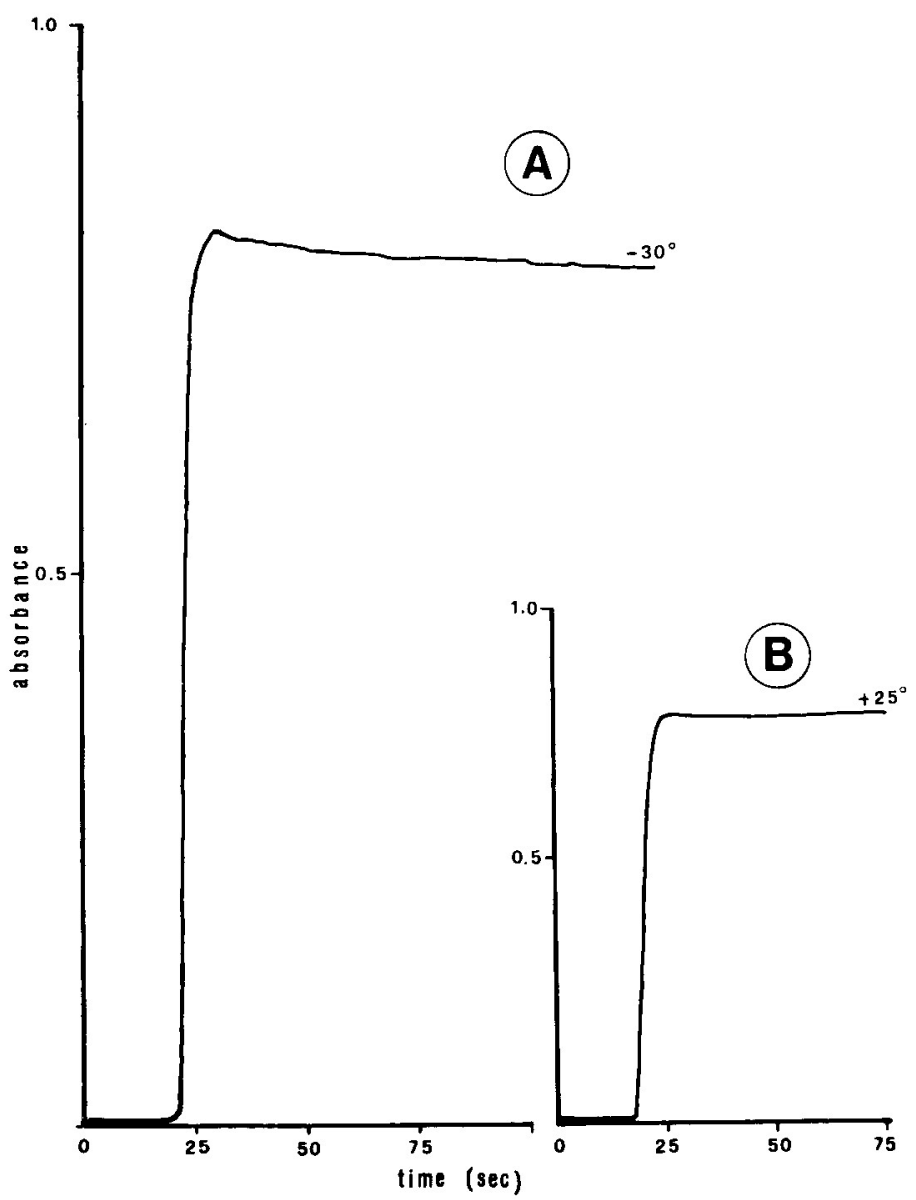

Fig. 3. A. The mixing kinetics when $50 \mu \mathrm{l}$ of a protein solution are rapidly injected into $2.5 \mathrm{ml}$ ethylene glycol/water mixture at $-30^{\circ} \mathrm{C}$ (viscosity $63 \mathrm{cP}$ ). B. The mixing kinetics at $25^{\circ} \mathrm{C}$ for the same amounts of protein and aqueous solution.

procedure, which has been described by Douzou [3], abrupt changes in the dielectric constant of the medium were prevented, thus reducing to a minimum the possibility of protein denaturation.

\section{The rate of $\mathrm{HbCO}$ oxidation}

The rate of $\mathrm{HbCO}$ oxidation represents a simple system for investigating the effect of temperature on a biochemical reaction. The reactions of myoglobin, deoxyhemoglobin and $\mathrm{HbO}_{2}$ with $\mathrm{K}_{3} \mathrm{Fe}(\mathrm{CN})_{6}$ at room temperature have been described by Antonini et al. [4]. According to Adair's theory of intermediate compounds of hemoglobin with ligands, the oxidation of fully liganded $\mathrm{Hb}_{4}(\mathrm{CO})_{4}$ by $\mathrm{K}_{3} \mathrm{Fe}(\mathrm{CN})_{6}$ may be visualized as occurring 
through the following initial steps:

$\mathrm{Hb}_{4}(\mathrm{CO})_{4} \underset{k_{\text {on }}}{\stackrel{k_{\text {off }}}{\rightleftharpoons}} \mathrm{Hb}_{4}(\mathrm{CO})_{3}+\mathrm{CO}$

$\mathrm{Hb}_{4}(\mathrm{CO})_{3}+\mathrm{Fe}^{3+} \stackrel{k_{\mathrm{ox}}}{\rightarrow} \mathrm{Hb}_{4}{ }^{+}(\mathrm{CO})_{3}+\mathrm{Fe}^{2+}$

In the initial part of the reaction, when the concentration of the intermediate species $\mathrm{Hb}_{4}{ }^{+}(\mathrm{CO})_{3}, \mathrm{Hb}_{4}{ }^{2+}(\mathrm{CO})_{2}$, etc., can be assumed to be negligible,

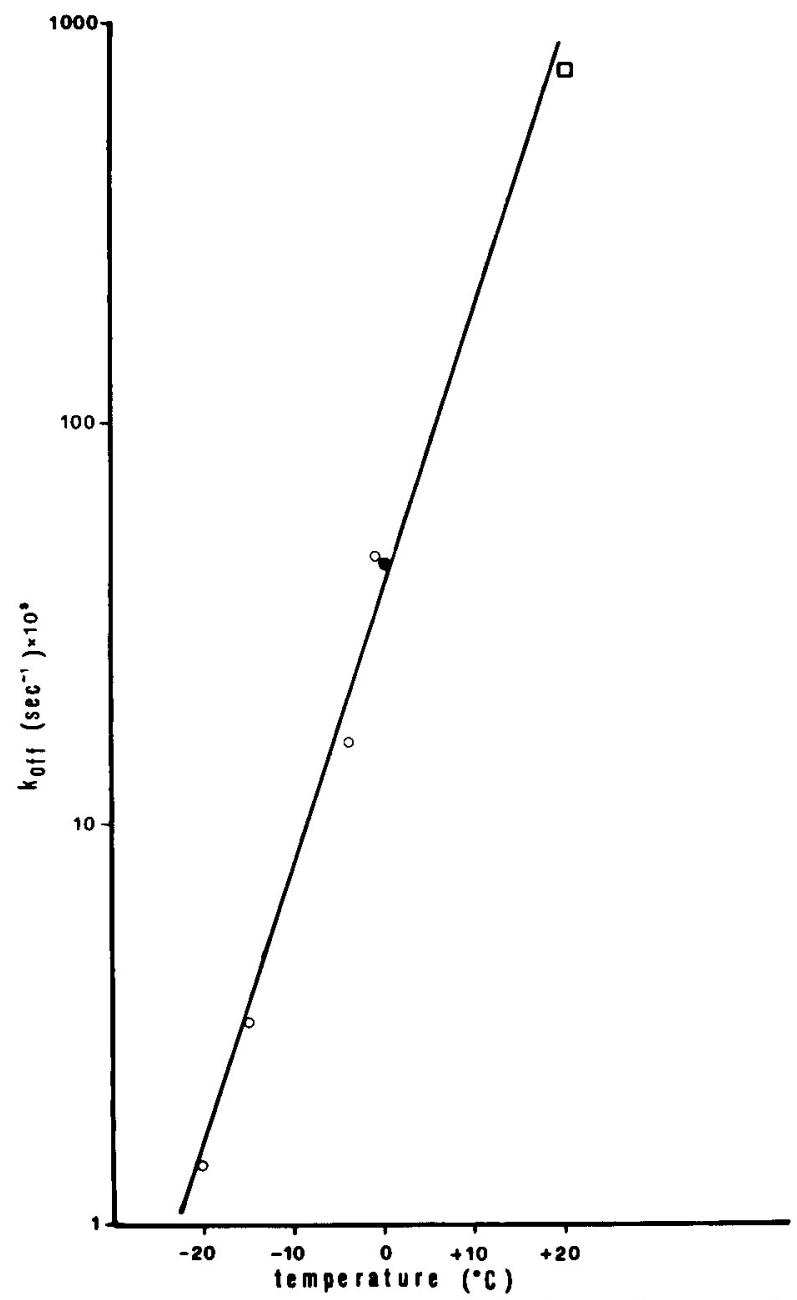

Fig. 4. Logarithmic behavior of the $k_{\text {off }}$ values as calculated from Eqn. 4 in the presence $(0)$ and in the absence $(\bullet)$ of ethylene glycol, and intrapolated from the data of Sharma et al. (口). The buffer for each experimental point was prepared according to Douzou [3], and hence the experimental $\mathrm{pH}$ can be considered to be approximately 7.4 . 
the kinetic equation for the disappearance of the $\mathrm{Hb}_{4}(\mathrm{CO})_{4}$ species is as follows:

$\frac{\mathrm{d}\left[\mathrm{Hb}_{4}(\mathrm{CO})_{4}\right]}{\mathrm{d} t}=-\frac{k_{\mathrm{off}} \times k_{\mathrm{ox}}\left[\mathrm{Fe}^{3+}\right]}{k_{\mathrm{on}}[\mathrm{CO}]+k_{\mathrm{ox}}\left[\mathrm{Fe}^{3+}\right]} \times\left[\mathrm{Hb}_{4}(\mathrm{CO})_{4}\right]$

Under conditions where $k_{\text {on }}[\mathrm{CO}]<<k_{\text {ox }}\left[\mathrm{Fe}^{3+}\right]$, Eqn. 3 reduces to

$\frac{\mathrm{d}\left[\mathrm{Hb}_{4}(\mathrm{CO})_{4}\right]}{\mathrm{d} t}=-k_{\mathrm{off}}\left[\mathrm{Hb}_{4}(\mathrm{CO})_{4}\right]$

Fig. 4 shows the values of $k_{\text {of }}$ obtained from experiments in which $200-$ 400 -fold molar excess of $\mathrm{K}_{3} \mathrm{Fe}(\mathrm{CN})_{6}$ was mixed rapidly into a solution of $\mathrm{Hb}_{4}(\mathrm{CO})_{4}$ at various temperatures, in the absence and presence of ethylene glycol. Eqn. 4 was used to calculate $k_{\text {of } f}$ from the increase the absorbance at $630 \mathrm{~nm}$ due to the oxidation of the protein. It is worthwhile to note that the value of $k_{\text {off }}$ obtained by Sharma et al. [5] using a completely different experimental procedure is in good agreement with the extrapolation of the data at subzero temperatures reported in this paper. Practically no difference is found either between the value of $k_{\text {of } f}$ obtained at $0^{\circ} \mathrm{C}$ in the presence and in the absence of ethylene glycol, indicating that no major configurational change in the hemoglobin structure was caused by the antifreezing agent.

Fig. 4 also shows that the velocity of the dissociation reaction is markedly affected by temperature, the apparent energy of activation being about 23 $\mathrm{kcal} / \mathrm{mol}$ at $\mathrm{pH} 7.4$, in agreement with the results obtained by Dalziel and O'Brien [6] for the dissociation of the last oxygen molecule from $\mathrm{Hb}_{4}\left(\mathrm{O}_{2}\right)_{4}$.

\section{SIMPLIFIED DESCRIPTION OF THE METHOD AND ITS ADVANTAGES}

The use of a brass, moplen-covered cuvette holder, suitable for spectrophotometric measurements at subzero temperatures down to $-40^{\circ} \mathrm{C}$ is described. Temperature equilibration times are of the order of $10-15$ min using either a $50 \%(\mathrm{v} / \mathrm{v})$ mixture of ethylene glycol with water or pure ethylene trichloride as coolant.

The major advantages of this method are: (1) the possibility of working at very constant temperature in the cuvette down to $-40^{\circ} \mathrm{C}$ without temperature drift and in a fully anaerobic compartment; (2) the possibility of using a variety of hydroorganic solvents with a specific viscosity up to about $60 \mathrm{cP}$ without compromising the full miscibility of two reactants, even if the mixing time is as long as 1.min under the worst conditions; (3) the possibility of performing not only static studies such as absorbance and spectrum measurements, but also kinetic studies; (4) the possibility of studying at subzero temperature biochemical reactions which are too fast at room temperature, thus allowing the measurement of the rate constant of the intermediate reactions. As an example we report the rate of oxidation of the fully liganded hemoglobin molecule $\mathrm{Hb}_{4}(\mathrm{CO})_{4}$ at different temperatures, from which the rate constant of the reaction $\mathrm{Hb}_{4}-$ $(\mathrm{CO})_{4} \leftrightharpoons \mathrm{Hb}_{4}(\mathrm{CO})_{3}+\mathrm{CO}$ can be calculated

\section{ACKNOWLEDGEMENTS}

We thank Professors M. Perrella and L. Rossi-Bernardi for their helpful suggestions and discussion. This study was supported in part by a grant from the Consiglio Nazionale delle Ricerche, Rome. 


\section{REFERENCES}

1 Maurel, P., Travers, F. and Douzou, P. (1974) Anal. Biochem. 57, 555-563

2 Kilmartin, J.V. and Rossi-Bernardi, L. (1971) Biochem. J. 124, 31-45

3 Douzou, P. (1977) in Cryobiochemistry: An Introduction. Academic Press, London

4 Antonini, E., Brunori, M. and Wyman, J. (1965) Biochemistry 4, 545-551

5 Sharma, V.S., Schmidt, M.R. and Ranney, H.M. (1976) J. Biol. Chem. 251, 42674272

6 Dalziel, K. and O'Brien, J.R.P. (1961) Biochem. J. 78, 236-245 